\title{
Comparison study of the effects of high hydrostatic pressure per se and high argon pressure on urate oxidase-ligand stabilization
}

Authors

Thierry Prangéa**, Philippe Carpentier ${ }^{\text {bc }}$, Anne-Claire Dhaussy ${ }^{\mathrm{d}}$, Peter van der Linden ${ }^{\mathrm{e}}$, Eric Girard ${ }^{\mathrm{f}}$ and Nathalie Colloc' ${ }^{\mathrm{g} *}$

aCiTCoM UMR 8038, CNRS, Université de Paris, Faculté de Pharmacie, 4, Av de l'Observatoire, Paris, 75006, France

'Université Grenoble Alpes CEA CNRS, IRIG-LCBM UMR 5249, Grenoble, 38000, France

'ESRF, the European Synchrotron, Grenoble, 38000, France

${ }^{\mathrm{d} N o r m a n d i e}$ Univ., Ensicaen, CNRS, CRISTMAT UMR 6508, Caen, France

${ }^{e}$ ESRF, PSCM (Partnership for Soft Condensed Matter), Grenoble, 38000, France

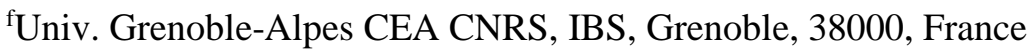

ISTCT UMR 6030, CNRS Université de Caen-Normandie CEA, centre Cyceron, bd Becquerel, Caen, 14074, France

Correspondence email: thierry.prange@ parisdescartes.fr; colloch@cyceron.fr

Synopsis Urate oxidase structures under high hydrostatic pressure per se and high argon pressure have been analysed, deciphering the basis of the protein-ligand stabilisation by pressure and the formation of a transient intermediate dimeric sub-state during the pressure-induced dissociation.

Abstract The stability of the tetrameric enzyme urate oxidase in complex with an excess of 8azaxanthine was investigated either under high hydrostatic pressure per se or under a high pressure of argon. The active site is located at the interface of two subunits, and the catalytic activity is then directly related to the tetramer integrity. This study demonstrates that applying pressure to a protein-ligand complex drives the thermodynamic equilibrium towards the ligand saturation of the complex, revealing a new binding site. A transient dimeric intermediate occurring during the pressure-induced dissociation process is characterized under argon pressure and excited sub-states of the enzyme occurring during the catalytic cycle can be trapped by pressure. The comparison of the different structures under pressure infers an allosteric role of the internal hydrophobic cavity where argon is bound, since this cavity gives the necessary flexibility for the active site to function.

Keywords: homotetramer, dissociation, enzymatic mechanism, argon, high pressure, HPMX 


\section{Introduction}

Pressure is a reversible thermodynamic variable, which increases the energy of biochemical systems and hence allows access to their low-lying excited states (Akasaka, 2006; Akasaka et al., 2013; Espada et al., 2016; Frauenfelder et al., 1990, 2007; Winter, 2019; Frauenfelder et al., 2009). Studies of proteins under pressure also give access to their dynamic behavior in excited states, and to properties of their transient conformational states. Many studies using NMR or crystallography under high hydrostatic pressure have demonstrated that these high energy conformers are functionally relevant, designed either as functional or kinetic intermediates (Louis \& Roche, 2016; Nielsen et al., 2013; Williamson \& Kitahara, 2019; Kalbitzer et al., 2013; Fourme, Girard et al., 2012; Collins et al., 2011; Dhaussy \& Girard, 2015; Fourme et al., 2009). These conformational states correspond to local minima in the energy landscape of a given protein along its reaction pathways.

Internal protein cavities present in the native state play an important role in pressure-induced structural modifications. Upon increasing pressure, above a critical value, cavities either collapse or become hydrated. Both processes drive pressure-induced denaturation, and trigger the unfolding process (Collins et al., 2005; Nagae et al., 2012; Xue et al., 2019). However, proteins partial unfolding behavior is already observed at lower pressure (Fuglestad et al., 2017; Nagae et al., 2012; Silva \& Weber, 1993; Xue et al., 2019). More specifically, when high pressure is applied to multimeric structures, denaturation usually begins by the dissociation of subunits, leading to lower order oligomeric states (Winter, 2019). This process is likely due to the fact that the association of subunits is stabilized by polar and ionic bonds that are the first to be disrupted by pressure.

Noble gases such as xenon, krypton and more recently argon are known to map hydrophobic tunnels and cavities within proteins (Prangé et al., 1998), deciphering pathways for gaseous ligands like molecular oxygen, carbon monoxide or hydrogen (Colloc'h et al., 2017; Knapp et al., 2009; Kalms et al., 2016; Engilberge et al., 2020; Luna et al., 2012, 2008; Tilton et al., 1984; Whittington et al., 2001; Hahn et al., 2021; Winter et al., 2011; Montet et al., 1997).

In the present study, we investigate the pressure-induced structural effects on the tetrameric enzyme urate oxidase (uricase; EC 1.7.3.3; UOX), with a competitive inhibitor (8-azaxanthine) bound at the interface between subunits. The UOX/8-azaxanthine complex appears to be a suitable model system to study the effect of pressure on the stability of an enzyme-ligand complex.

UOX is involved in the purine degradation pathway and is active as a homotetramer. Without any cofactor, it catalyzes the oxidation of uric acid to 5-hydroxy-isourate in the presence of molecular oxygen, and generates hydrogen peroxide as by-product (Scheme 1). UOX from Aspergillus flavus in complex with the competitive inhibitor 8-azaxanthine (8-aza) crystallizes in the orthorhombic space 
group I222 with one monomer per asymmetric unit (Colloc'h et al., 1997). The tetramer is composed of two face-to-face 16-stranded $\beta$-barrel dimers, delimiting a central tunnel of $50 \AA$ long and $12 \AA$ in diameter. The dimer composed of two face-to-face monomers is termed A-B, while the dimer that forms the 16-stranded $\beta$-barrel is termed A-C (Fig. 1, upper part). The active site is located at the interface between monomers $\mathrm{A}$ and $\mathrm{C}$, where the ligand (here the 8-aza molecule) is hydrogen-bonded to the side chains of the two tweezer amino acids Arg 176 and Gln 228, and to the main chain nitrogen of the Thr $57 *$ (* strands for the symmetric monomer), and forms a $\pi-\pi$ stacking interaction with Phe 159 (Colloc'h et al., 1997). In the peroxo hole, on the opposite side of the phenylalanine, the water molecule responsible for the catalytic hydration step is hydrogen-bonded between side chains of Asn 254 and Thr $57^{*}$, acting as peroxo hole tweezers. A well conserved H-bond network connects the ligand to the catalytic water molecule, through two water molecules, the His 256 side chain, and the catalytic diad Lys $10^{*}$ and Thr $57 *$ side chains. This network was proposed to act as a proton shuttle during the different steps of the reaction mechanism (Gabison et al., 2008, 2010, 2011; Wei et al., 2017; Bui et al., 2014; McGregor et al., 2021).

The functional relevance of a large buried hydrophobic cavity close to the active site in each monomer was probed using both crystallography under moderate pressure of noble gas (less than $5 \mathrm{MPa}$ ) and high pressure (Colloc'h \& Prangé, 2014; Girard et al., 2010). This cavity was proposed to have an allosteric role acting as a connecting vessel to provide the flexibility necessary to the neighboring active site for function.

Above a critical hydrostatic pressure, which depends on the ligand presence and concentration, the tetramer in complex with 8-aza slowly begins to unfold (Girard et al., 2010). In order to determine the different factors involved in UOX pressure-induced destabilization, we compare the direct effects of hydrostatic pressure per se with the effects of argon-mediated pressure on the structure of a complex UOX/8-aza produced in excess of ligand. In the following, the two types of pressure, either hydrostatic pressure per se and high argon pressure, will be referred to as HHP and HArP respectively, and each $(P, T)$ state of UOX crystals will be designated by the acronym "UOX-type-pressure in MPa-temperature in K or room temperature (RT)"'.

This comparative study aims at investigating the first glimpse of the pressure-induced UOX tetramer dissociation, to identify a potential intermediate sub-state, and to confirm the allosteric role of the cavity in the enlargement of the active site necessary for efficient enzymatic activity.

\section{Materials and methods}

\subsection{Crystallization}


Purified urate oxidase from Aspergillus flavus expressed in S. cerevisiae was a gift from the Sanofi Company (Montpellier, France). 8-azaxanthine was purchased from Sigma-Aldrich (Lyon, France). Crystals were routinely prepared at room temperature $(291 \mathrm{~K})$ by mixing $20 \mu \mathrm{L}$ of enzyme $(20 \mathrm{mg} / \mathrm{mL}$ at $\mathrm{pH} 7.5-8.0$ ) with $20 \mu \mathrm{L}$ of a $8 \%$ PEG 4000 solution at the same $\mathrm{pH}$ (buffer $=$ Tris/acetate $50 \mathrm{mM}$ ), in the presence of a large excess of 8 -azaxanthine $(10 \mathrm{mg})$. Large diamond-shape colorless crystals usually grow in about two days. They were stabilized by increasing the PEG concentration to $10 \%$ in the final solution. They usually grow with approximate size 0.4 x $0.6 \mathrm{~mm}$, and were stable at $291 \mathrm{~K}$ over several weeks.

\subsection{Pressurization cells}

High hydrostatic pressure macromolecular crystallography (HPMX) were performed using a Diamond Anvil Cell (DAC) described previously (Fourme et al., 2001; Fourme, Girard et al., 2012; Girard et al., 2007). We used two large aperture DACs designed by Roger Fourme and colleagues, and manufactured by the BETSA Company (Nangis, France). The DACs have an Inconel gasket elastic enough to allow a reversible decrease of pressure, a drilled hole of $400 \mu \mathrm{m}$ in diameter and $200 \mu \mathrm{m}$ depth and an aperture of $90^{\circ}$ allowing a complete data set to be recorded on crystals belonging to highly symmetric space groups in a single rotation. The pressure within the DAC compression chamber was monitored through the pressure-dependent fluorescence of a ruby chip used as an internal probe. We used the DACs to compress UOX crystals at 210 and $310 \mathrm{MPa}$, for which the pressure transmitter is solely the mother liquor.

At low argon pressure, 3.5 and $6.5 \mathrm{MPa}$, we used a quartz capillary pressure cell, in which the pressure is transmitted by the static pressurized argon gas (Schiltz et al., 1994). At moderate argon pressure, 12 and $22 \mathrm{MPa}$, we used the "soak-and-freeze" method as described in (Lafumat et al., 2016). At high argon pressure (60 MPa, $100 \mathrm{MPa}, 150 \mathrm{MPa}$ and $200 \mathrm{MPa}$ ), we used the same approach but with a twostage compressor apparatus to reach higher pressure (van der Linden et al., 2014). For these two latter techniques, UOX crystals are compressed by static gaseous argon prior to being frozen in the liquid phase of argon at $77 \mathrm{~K}$ while they are still under pressure. They were thereafter depressurized at cryogenic temperature.

\subsection{Data recording and processing}

Three high hydrostatic pressure (HHP) data collections with a DAC were recorded at room temperature on UOX in the presence of an excess of 8-aza (UOX-HHP-0.1-RT as a reference, UOX-HHP-210-RT and UOX-HHP-310-RT) at the CRISTAL beamline (SOLEIL synchrotron, Gif sur Yvette, France), with a Rayonix SX-165 detector at an incident X-ray wavelength $\lambda=0.58183 \AA$ ( $21 \mathrm{keV})$, a beam size of $50 \mu \mathrm{m}$ x $50 \mu \mathrm{m}$ and a crystal-to-detector distance of $124.5 \mathrm{~mm}$. Data collection at short wavelengths 
reduces the absorption of the diamond windows and increases the accessible reciprocal space allowing higher resolution to be reached (Fourme, Honkimäki et al., 2012).

Particular attention was paid to minimize radiation damage for data collections at room temperature, in order to avoid misinterpretations due to potential unwanted X-ray induced structural changes. Figure S1 illustrates the typical strategy used to collect data on a large crystal which fitted the DAC cavity well. The DAC is placed on a support and is vertically rotated with an available rotation range of $-45^{\circ}$ to $45^{\circ}$ thanks to the large geometrical opening of our pneumatic DAC (Fourme et al., 2001; Fourme, Girard et al., 2012). Prior to data collection, the cavity is centered with X-rays using a highly attenuated beam (dashed square in Fig S1). A typical data collection is thus performed with $50 \mu \mathrm{m}$ x $50 \mu \mathrm{m}$ beam size on several zones (blue squares) using to a $10^{\circ}$ rotation at each position.

Hence, large crystals of UOX $\left(300 \times 300 \times 180 \mu \mathrm{m}^{3}\right)$ that fit optimally into the DAC cavity were selected to have maximum of diffracting material and power. With such large crystals compared to the small beam, full data collection on a single crystal at a given pressure were performed by merging 3 to 5 partial datasets of 20 to $30^{\circ}$ rotation ranges collected on well separated zones with at least $50 \mu \mathrm{m}$ of translation between each of them. In the present study, a single crystal was exploited for data measurements at ambient pressure by collecting $20^{\circ}$ data from each of 5 zones, and a second crystal was exploited for data measurements at high pressure by collecting $30^{\circ}$ data on each of 3 zones situated on one side of the crystal, at $210 \mathrm{MPa}$ and $30^{\circ}$ each from 3 zones on the other side of the sample at 310 MPa. This corresponds to a translation of more than $100 \mu \mathrm{m}$ between the two sample parts used for data collection. Moreover, owing to the diffracting power of the bulky crystals and to the orthorhombic I222 space group, the complete data set was collected with an exposure time of $4 \mathrm{~s}$, an oscillation range of $1^{\circ}$ per frame over a full rotation of $90^{\circ}$, and an X-ray beam flux of $1.9 \times 10^{10}$ photon/s (26 fold attenuated) at $21 \mathrm{keV}$.

The two data collections under argon pressure in quartz capillaries were performed at room temperature on UOX in the presence of an excess of 8-aza (UOX-HArP-3.5-RT and UOX-HArP-6.5-RT) with a MAR CCD Mosaic detector at the MAX II synchrotron, beamline I711 (Lund, Sweden), with $1^{\circ}$ rotation per frame and a full rotation of $120^{\circ}$. The six other data collections under argon pressure $(12,22,60$, 100,150 and $200 \mathrm{MPa}$ ) were performed at $100 \mathrm{~K}$ on UOX in the presence of an excess of 8-aza (UOXHArP-12-T100, UOX-HArP-22-T100, UOX-HArP-60-T100, UOX-HArP-100-T100, UOX-HArP150-T100, and UOX-HArP-200-T100) using the flash-cooled crystals recovered from the pressurization devices, with a Pilatus 6M detector at the ESRF beamline ID30B (Grenoble, France)(McCarthy et al., 2018), with $0.1^{\circ}$ rotation per frame and the same range of $120^{\circ}$. To discriminate argon atoms from water molecules or other ions, the six data sets were collected at a wavelength of $1.7 \AA$, to locate argon atoms using their anomalous signal at low energy (Fig. S2).

All data sets were processed using the XDS software (Kabsch, 2010). The resolution limits were determined using various criteria in the highest bin, including a $\mathrm{I} / \sigma(\mathrm{I})$ ratio around 2 , and a $R_{\text {meas }}$ lower 
than $80 \%$. The integrated intensities were scaled and merged with SCALA and TRUNCATE, and the structures were solved by molecular replacement with MOLREP, all from the CCP4 suite of programs (Winn et al., 2011) . Molecular replacement was performed using the pdb 2iba structure as the starting model for the data in the I222 space group and a reconstructed dimer of $2 i b a$ for the data in the P $2{ }_{1}{ }_{2} 2$ space group. Argon sites and their occupancy were initially estimated from their peaks in anomalous $\Delta \mathrm{f}^{\prime \prime} \pm$ maps, using the neighboring sulfur atoms (from Met and Cys residues) as calibration (Fig. S2). All data were refined with REFMAC5 (Murshudov et al., 1997) and the resulting models analyzed and rebuilt with the graphic tool Coot (Emsley et al., 2010) All water molecules in the final models were kept only if they were located at correct $\mathrm{H}$-bond distances and if their unconstrained $B$-factors remained lower than $60 \AA^{2}$.

The data processing and refinement statistics are given in the Tables 1 and 2, respectively. The final models and associated data sets were deposited in the Protein Data Bank (the pdb files IDs are reported at the end of Table 2).

Calculations of cavity volumes were performed using VOIDOO (Kleywegt \& Jones, 1994) with a grid spacing of $0.6 \AA$ and a probe radius of $1.1 \AA$, using 20 randomly generated orientations of the protein model. Calculations of thermodynamic parameters were performed using the PISA program (Krissinel, 2015) from the CCP4 package. Figures were prepared using PYMOL (Version 2.4 Schrodinger, LLC).

\section{Results}

\subsection{UOX structures under high hydrostatic pressure per se (HHP)}

Although recorded at different synchrotrons, the consistency and reproducibility of all the experiments under pressure are illustrated by the similar linear dependencies of the unit cell volume of UOX with pressure (Fig. S3).

In the present study, three structures of UOX in the presence of an excess of 8-aza were refined from data sets collected at the CRISTAL beamline: a reference data set at ambient pressure (UOX-HHP-0.1RT), and two high pressure data sets at 210 and $310 \mathrm{MPa}$ (UOX-HHP-210-RT and UOX-HHP-310-RT respectively). The pressure degrades the quality of the crystal, with a resolution decrease from $1.9 \AA$ to $2.15 \AA$ and $2.4 \AA$ for the UOX-HHP-0.1-RT, UOX-HHP-210-RT and UOX-HHP-310-RT structures respectively, while the average thermal $B$-factors increase from $21 \AA^{2}$ to $29 \AA^{2}$ and $49 \AA^{2}$. Consistently, the number of modelled water molecules decreases from 261 to 179 and 115 . We observe a clear destabilization of UOX at $310 \mathrm{MPa}$, which is close to the pressure of denaturation since at $340 \mathrm{MPa}$ UOX crystals weakly diffract and dissolve at $400 \mathrm{MPa}$.

The estimated dose per irradiation zone was calculated using the program RADDOSE-3D (Bury et al., 2018), taking the experimental parameters described above into account. The average dose on each exposed region was evaluated to be about $11 \mathrm{kGy}$ (Average Dose Exposed region) and the maximum 
dose to be $95 \mathrm{kGy}$. Hence, the present data collections were recorded with absorbed doses one order of magnitude below the established values that should not be exceeded to solve structures at room temperature (100 - $500 \mathrm{kGy}$ ) (Leal et al., 2013; de la Mora et al., 2020). A recent study experimentally demonstrated that, when structures are solved at room temperature with low dose, minimizing global radiation damage, the specific radiation damage that would modify the structures are of much less concern (Gotthard et al., 2019). This ensures that the differences between the three UOX-HHP-RT structures, which are discussed below, are unlikely to be related to radiation damage issues. This strategy was reinforced by a recent study experimentally showing the benefits of using high X-ray energies for macromolecular crystallography (Storm et al., 2021).

The structural differences between ambient and high-pressure structures remain small. The UOX-HHP0.1-RT structure displays an r.m.s deviation on the C $\alpha$ of $0.18 \AA$ with UOX-HHP-210-RT and $0.19 \AA$ with UOX-HHP-310-RT (Fig. S4). The main difference between these structures is, as expected, the diminution of the volume of the internal hydrophobic cavity, of $38 \%$ between UOX-HHP-210-RT and UOX-HHP-0.1-RT. This decrease is consistent with that of $16 \%$ at $150 \mathrm{MPa}$ compared to ambient pressure described in previous work (Girard et al., 2010). At $310 \mathrm{MPa}$, there is no further contraction, but a slight expansion of $8 \%$ compared to UOX-HHP-210-RT. However, the calculation of the cavity volume might be imprecise for a structure at such a moderate resolution. No electron density for any water molecules that could have penetrated the cavity was evidenced whatever the applied pressure. The main chain overall thermal $B$-factors increased on average by $9 \AA^{2}$ between the two UOX-HHP0.1-RT and UOX-HHP-210-RT structures. Interestingly, amongst the 47 least pressure-sensitive residues (i.e. with B-factors increasing by less than $5 \AA^{2}$ ), 13 are located along the central tunnel and 19 belong to the A-C interface forming the $\beta$-barrel, among which 10 are specifically located in the active site. In contrast, 23 amongst the 44 most pressure-sensitive residues (i.e. with $B$-factors increasing by more than $13 \AA^{2}$ ) belong to the face-to-face A-B interface (Fig. 1, lower part). There is a large increase of average $B$-factor (19 $\AA^{2}$ ) between the two UOX-HHP-210-RT and UOX-HHP-310-RT structures, revealing that the tetramer becomes destabilized by pressure. Here also, half of the most sensitive residues (i.e. with B-factors increasing by more than $24 \AA^{2}$ ) belong to the A-B interface (Fig. S5). This behavior strongly suggests that the pressure-induced destabilization appears precisely at this face-to-face interface, which therefore represents the weak point of the quaternary structure leading to the disruption of the tetramer.

The active site, located at the $\beta$-barrel A-C interface, is clearly enlarged by pressure. This expansion can be quantified by the distance between the residues Asn 254 and Thr 57* (the clamp holding the catalytic water termed W1) that increases from $5.35 \AA$ (UOX-HHP-0.1-RT) to $5.63 \AA$ (UOX-HHP-210RT) and to $5.88 \AA$ (UOX-HHP-310-RT). Notably, there is a backward displacement of Asn 254 side chain that disrupts the H-bond with W1 (distance of 2.8, $3.2 \AA$ and $3.4 \AA$ for UOX-HHP-0.1-RT, UOXHHP-210-RT and UOX-HHP-310-RT respectively), as shown in Fig. 2. 
On the other hand, the positions of 8-aza and the catalytic water W1 above the inhibitor are observed to be very stable. Similarly, the conserved network of H-bonds linking 8-aza to the catalytic water molecule W1, through two conserved water molecules $\left(8\right.$-aza $\rightarrow \mathrm{W} 2 \rightarrow \mathrm{W} 3 \rightarrow$ His $256 \rightarrow$ Lys $10^{*} \rightarrow \mathrm{Thr}$ $57^{*} \rightarrow \mathrm{W} 1$ ), remains almost unmodified, except the W2-W3 distance that expands from $3 \AA$ (UOXHHP-0.1-RT) to $3.3 \AA$ (UOX-HHP-210-RT and UOX-HHP-310-RT).

Interestingly, at high pressure, a second 8-aza molecule is observed at the entrance of the channel leading to the active site, while this latter is still occupied by the first ligand. The occupancies of this second ligand are estimated to be $50 \%$ and $40 \%$ in the refined structures UOX-HHP-210-RT and UOX-HHP-310-RT respectively. This second inhibitor is undetectable at $0.1 \mathrm{MPa}$. It is located between the two subunits of the $\beta$-barrel and stabilized through a $\pi$-stacking interaction with Phe 258 , and also loosely stabilized by the formation of H-bonds with Asp 58* and Lys $61^{*}$ side chains. A water molecule located above the ligand is $\mathrm{H}$-bonded to the Asp 58* side chain, an environment that closely mimics the active site. In addition, a network of hydrogen-bonds links the two inhibitors, from the N9 atom of the first 8-aza molecule to the $\mathrm{O} 6$ atom of the second one through two water molecules, W2 and a new one termed here W4 (Fig. 3).

\subsection{UOX structures under argon pressure (HArP)}

Previous studies of UOX structures under pressurized noble gas have shown that the main gas binding site is the large internal hydrophobic cavity close to the active site. At higher pressure, $\mathrm{Xe}$ and $\mathrm{Kr}$ also bind at the bottom of a surface pocket within each subunit with a low occupancy (Colloc'h et al., 2011; Marassio et al., 2011). In the present study, 8 structures of UOX in presence of an excess of 8 -aza under Ar pressure were refined (UOX-HArP-3.5-RT, UOX-HArP-6.5-RT, UOX-HArP-12-T100, UOXHArP-22-T100, UOX-HArP-60-T100, UOX-HArP-100-T100, UOX-HArP-150-T100, and UOXHArP-200-T100) showing that argon binds to the internal cavity with occupancies increasing with the applied pressure from $20 \%$ at $3.5 \mathrm{MPa}$ to nearly saturation at $150 \mathrm{MPa}$ (Fig. S6). Because of its high critical pressure, argon becomes visible in the minor binding site only at $12 \mathrm{MPa}$ with an occupancy of $25 \%$ that increases to $50 \%$ at $100 \mathrm{MPa}$ and $80 \%$ at $150 \mathrm{MPa}$. No other binding sites are evidenced in the anomalous maps, demonstrating that noble gases have mainly two binding sites in the monomer of UOX (Fig. S2 and S7).

Interestingly, a high pressure of argon of $60 \mathrm{MPa}$ and above induces a loss of two of the 222-fold symmetries in the $\alpha_{4}$ homotetramer, leading to a less symmetric $(\alpha \beta)_{2}$ homotetramer. Consequently, the crystal space group changes from I222 to $\mathrm{P} 2{ }_{1} 2_{1} 2$ (Fig. 4, upper part). This HArP-induced disruption of the symmetry at the A-B interface is interpreted as the very first step of pressure-induced dissociation of the tetrameric organization into a transient dimeric state constituted by the $\beta$-barrel A-C. The structural differences related to the $\alpha_{4} \rightarrow(\alpha \beta)_{2}$ transition within the tetramer are quantified by the least- 
squares deviations between main chain atoms of the A subunit with those of the B subunit within the AB dimer (Fig. 4, lower part). Surprisingly at a local level, the r.m.s. displacements appear rather low, while noticeable shifts are observed in five short regions, with a prominence for residues 123-125 in the A-B interface. In the I222 habit of the $\alpha_{4}$ tetramer, the 123-125 residues are in close contact with their symmetric mates. Hence, this segment needs to be refined as a two-orientation disordered loop to avoid unwanted steric clashes. This disorder is likely due to the averaging of the 222 local symmetry of the $\alpha_{4}$ tetramer over the 222 crystallographic symmetry. In the $(\alpha \beta)_{2}$ tetramer, the two-fold symmetry related to the segment 123-125 is no longer affected by a steric clash. This disorder is thus fully resolved and the segment 123-125 can be perfectly traced in the two independent chains.

Regarding the other striking regions, the two loops 50-52 and 264-267 are involved in the crystalline packing interface and the loop 196-202 is involved in the A-B interface. These three loops can be considered as the mobile parts of the monomer that further make the tetramer inner 222 symmetries to fit the crystallographic symmetries as well as possible. The residue Glu 22 is embedded in the loop 2126 which is always very disordered.

In the eight HArP structures, the active site remains unmodified whatever the argon pressure. The distance between the peroxo hole tweezers also remains unchanged (distance of 5.4 Å between Asn 254 and Thr 57* side chains), the H-bond between the catalytic water W1 and Asn 254 is unaffected, and the H-bond between W2 and W3 is conserved, contrary to what is observed in the HHP structures. However, and similarly to the HHP structures, a second 8-aza molecule becomes visible in the electron density map at $150 \mathrm{MPa}$ and $200 \mathrm{MPa}$, bound at the entrance of the channel leading to the active site. The occupancy of this second ligand is estimated to be about $30 \%$ in UOX-HArP-150-T100 and about $60 \%$ in UOX-HArP-200-T100. The same H-bond network links the two 8-aza molecules through W2 and W4 (Fig. 3) similarly to what is observed in the HHP structures.

\section{Discussion}

\subsection{Argon labelling}

Usually, argon labelling, like other noble gases, induces only marginal structural changes since it maintains a good isomorphism between labelled and non-labelled structures (Schiltz et al., 2003; Vitali et al., 1991). This results in very low r.m.s. deviations when comparing their $\mathrm{C} \alpha$ traces. The noble gas occupancies in binding sites of a given protein depend on both the atom physicochemical properties and the applied pressure. It can usually be modelled by the Hill-Langmuir isotherm saturation curve (Marassio et al., 2011) that can be written as:

$$
f=\frac{f_{\max \left(\frac{P}{P_{c}}\right)}}{1+\left(\frac{P}{P_{c}}\right)^{a}}
$$


where $P_{c}$ is the critical pressure at which the occupancy $f$ reaches half of its saturation $\left(f_{\max } / 2\right)$ and $\alpha$ is the curve steepness coefficient (or sigmoidality that reflects a cooperative binding). For a given site, the value of $P_{c}$ depends essentially on both the Henry's coefficient of the dissolved gas in the protein solution and on the gas polarizability (i.e. the protein/noble-gas interaction strength). $P_{c}$ is thus ranked as: $\mathrm{P}_{\mathrm{c}}{ }^{\mathrm{Xe}}<<\mathrm{P}_{\mathrm{c}}{ }^{\mathrm{Kr}}<<\mathrm{P}_{\mathrm{c}}{ }^{\mathrm{Ar}}$. Experimentally, the critical pressure to populate a given protein binding site is observed to be rather low for xenon ( 0.5 - $3 \mathrm{MPa}$ ), intermediate for krypton ( 1 - $20 \mathrm{MPa}$ ), and high for $\operatorname{argon}(\sim 50$ - $200 \mathrm{MPa})$. In a given binding site, the noble gas occupancies in UOX are, as expected, in the order of their polarizabilities (Fig. S6)(Quillin et al., 2000; Colloc'h et al., 2011).

Contrary to what happens in many cases where the number of binding sites increases with pressure (Colloc'h et al., 2017; Kalms et al., 2016; Engilberge et al., 2020; Prangé et al., 1998), we only observed two noble gas binding sites in UOX whatever the pressure. The main noble gas binding site highlights a putative dioxygen storage site, since the hydrophobic cavity where it binds was proposed to serve as a transient reservoir for dioxygen on its way to the active site (Colloc'h \& Prangé, 2014). The minor binding site is a surface pocket largely deepened in the presence of the gas and located in the vicinity of residues lining the central tunnel. Interestingly, this pocket is also deepened in UOX-HHP-210-RT structure (but not in UOX-HHP-310-RT), with however no exogenous molecule bound into it, revealing the intrinsic dynamics of this pocket.

\subsection{HArP reveals the first step of tetramer dissociation}

The most important feature observed in UOX HArP structures is a transition from the body-centered space group of the crystals to a less-ordered primitive space group. The transition I222 $\rightarrow \mathrm{P} 2{ }_{12}{ }_{12}$ is triggered by argon at a pressure between $22 \mathrm{MPa}$ and $60 \mathrm{MPa}$. This corresponds to a loss of a symmetry between the four equivalent monomers, according to the $(\alpha)_{4} \rightarrow(\alpha \beta)_{2}$ scheme.

This transition is not observed in the HHP structures when the pressure transmitter is solely the mother liquor. However, we can speculate that the cluster of pressure-sensitive residues along the A-B interface could be indicative of the future loss of the two-fold symmetry between these two monomers. Subdomains that are the most pressure sensitive usually indicate the presence of a mispacked state. In our case, this would correspond to the region encompassing the Asp 123 residue.

A thermodynamic analysis of the UOX monomer by PISA shows that the tetramer is, as expected, the most stable assembly $(\Delta \mathrm{G}=-164 \mathrm{kcal} / \mathrm{mol})$, and that both dimers are equally stable with a $\Delta \mathrm{G}=-50$ $\mathrm{kcal} / \mathrm{mol}$. Interestingly, their free energy of assembly dissociation is lower for the face-to-face A-B $\operatorname{dimer}\left(\Delta \mathrm{G}_{\text {diss }}=30 \mathrm{kcal} / \mathrm{mol}\right)$ than for the $\beta$-barrel A-C dimer $\left(\Delta \mathrm{G}_{\text {diss }}=42 \mathrm{kcal} / \mathrm{mol}\right)$, showing that the face-to-face dimer is thermodynamically less stable than the $\beta$-barrel dimer. In line with these calculations, the structures under very high argon pressure (60 MPa and above) confirm that the faceto-face dimer A-B seems to be less stable than the $\beta$-barrel dimer A-C, since pressure induces the 
disruption of the tetramer symmetry precisely at the A-B interface. We can then suggest, based on the loss of symmetry induced by a high pressure of argon, that pressure would begin to dissociate the tetrameric UOX via the formation of an intermediate A-C sub-state constituted by the most stable 16stranded $\beta$-barrel.

In contrast, it has been shown recently that controlled dehydration of UOX crystals from bacillus $s p$. $T B-90$, using the humid air and glue-coating method, induces a phase transition from a $\mathrm{P} 2{ }_{1}{ }_{1} 2$ space group to a I222 space group (Hibi et al., 2014, 2016; Hibi \& Itoh, 2021). Dehydration has an effect opposite to pressure, inducing a modification from a homotetramer with the four chains in the asymmetric unit to a more ordered tetramer with the 16 -stranded $\beta$-barrel dimer in the asymmetric unit.

\subsection{Comparison between HHP and HArP effects at $200 \mathrm{MPa}$}

The difference between hydrostatic pressure per se and high pressure induced by noble gas has been mainly studied in the context of high pressure nervous syndrome studies, to discriminate between the pure pressure effect and the pressure effect of breathing helium by divers. Theoretical studies on the NMDA receptor have shown that a pressure of $2.5 \mathrm{MPa}$ helium induces more deformation than a 2.5 MPa pressure per se, mainly through protein-lipid interactions (Bliznyuk et al., 2019). Although our globular model cannot be compared to a membrane-embedded protein, it is interesting to note that argon pressure induces a disruption of the symmetry not observed at a similar high pressure per se.

The UOX-HArP-200-T100 structure is closer to the UOX-HHP-210 RT structure than to the UOXHHP-310 RT structure (Fig. S4), suggesting that a part of the Ar pressure-induced structural modifications at $200 \mathrm{MPa}$ may arise from the direct effect of pressure (per se), even if it is difficult to take into account the effect due to the difference in data collection temperatures (100 K and RT).

\subsection{Tetramer stabilization by the inhibitor bound at interface}

A protein interacts with a ligand through a spatial reorganization, implying that the complexation process is associated with a volume change. Thus, applying pressure, which is thermodynamically conjugated to volume, modifies de facto the protein/ligand interaction by adjusting voids at the interface between the protein and its ligand. Pressure is a way to induce a denser packing, with a smaller volume at the interface, leading to a more stable complex. Moreover, pressure by exploring the conformational landscape could favor a sub-state corresponding to a local minima which in turn favors ligand binding (Levin et al., 2019; Luong et al., 2015; Winter, 2019).

We have previously shown by fluorescence spectroscopy experiments that UOX displays an enhanced pressure stability upon inhibitor binding, in a concentration-dependent manner (Girard et al., 2010). Without inhibitor, the pressure-induced dissociation of the tetramer (denaturation) was observed around 175-200 MPa. This limit is shifted toward higher pressure depending on the concentration of the 
inhibitor, around 220-250 MPa with an equimolar concentration and around $350 \mathrm{MPa}$ with an excess of 8-aza. The previously determined crystallographic structure of UOX under a hydrostatic pressure of $150 \mathrm{MPa}(\mathrm{pdb} 3 f 2 \mathrm{~m})$ was obtained in the presence of an equimolar concentration of 8-aza. With such a ratio, the diffraction was lost above $200 \mathrm{MPa}$. The stabilizing effect of 8 -aza in excess is here confirmed, since diffraction was now lost at about $400 \mathrm{MPa}$. This result highlights that the ligand bound at the interface strengthens the dimer and further protects the tetrameric organization against pressure effects. Moreover, both HHP and HArP show that a second inhibitor molecule is stabilized in the channel connecting the solvent to the active site. The Lys $61 *$ residue, which is H-bonded to this second 8-aza, is amongst the least pressure-sensitive residues, confirming that pressure consolidates this area.

In the previous study of UOX at $150 \mathrm{MPa}$ in the presence of an equimolar concentration of 8-aza, we observed that three loops surrounding the channel leading to the active site were particularly pressuresensitive with the largest $B$-factor increases (Girard et al., 2010). In the presence of an excess of 8-aza, the $B$-factor increase of two of these loops (51-55 and $161-173)$ remains average, confirming that 8 aza in excess stabilizes the active site against the effect of pressure. On the other hand, the loop $260-$ 275 , which is part of the face-to-face A-B interface, still displays a high pressure sensitivity, in line with a destabilization of this interface. It is interesting to note that the two loops $51-55$ and 260-275 are also those which differ between the two A and B monomers when the symmetry is disrupted.

\subsection{Differences of temperature in data collections}

HHP data collections within a DAC and HArP data collections in capillaries below $7 \mathrm{MPa}$ were performed at room temperature, but at $100 \mathrm{~K}$ for HArP data collections at $12 \mathrm{MPa}$ and above. The mosaicity of the crystals is indeed affected upon freezing (Table 1). The structural modifications and the intrinsic dynamics of flexible loops induced by pressure lead to a degradation of the order and resolution together with an associated increase of thermal $B$-factors. This is especially visible at 310 $\mathrm{MPa}$, a pressure quite close to that which leads to a total loss of diffraction. On the other hand, the freezing of crystals under high pressure of Ar leads experimentally to immobilise transient sub-states in crystals, which thus display diffraction to higher resolution. Hence, the second 8-aza becomes clearly more visible in UOX-HArP-200-T100 structure than in both UOX-HHP-210-RT and UOX-HHP-310RT MPa structures. However, the treatment under argon pressurization followed by a depressurization step then a freezing step is quite difficult to conduct, leading sometimes to a degradation of the quality of diffraction.

\subsection{HHP reveals an excited sub-state of UOX catalytic cycle}

The enzyme conformation in the UOX-HHP-210-RT and UOX-HHP-310-RT structures, that display a broader active site characterized by an elongated peroxo hole tweezers (Asn 254 - Thr 57*), can 
correspond to a sub-state where the active site needs to accommodate a larger ligand. This occurs during the catalytic mechanism, when the non-planar 5-hydroxy-isourate product is bound before release. The larger distance between Asn 254 and Thr 57* also corresponds to a sub-state in which molecular oxygen is bound in the active site in place of the catalytic water (Colloc'h \& Prangé, 2014).

In previous work, it was proposed through the dissection of the complete UOX catalytic reaction that a base-oxidative-system (BOS) plays a central role in the mechanism (Gabison et al., 2011). It consists of the peroxo hole tweezers Thr 57*/Asn 254 acting together with the triad Lys 10*/His 256/Lys 61* which would deprotonate and then extract an electron from uric acid. The clear stabilization of Lys $61^{*}$ upon pressurization suggests again that pressure stabilizes an active sub-state of UOX that occurs along the catalytic cycle.

Interestingly, the proton shuttle mechanism (Gabison et al., 2010, 2011), which runs from 8-aza to W1 through W2, W3, His 256, Lys 10* and Thr 57* is weakened at 210 and $310 \mathrm{MPa}$. Indeed, at these pressures, the H-bond between W2 and W3 becomes elongated, since W2 is engaged in an H-bond with W4 that interlinks the two inhibitors. The HHP structures thus suggest the existence of a mechanism with two sub-states, a sub-state that processes the first ligand through the proton pathway exchange (the proton shuttle) and a sub-state where an H-bond system stabilizes the entrance of a second ligand.

Similarly, Asn 254, which is displaced backward by pressure, has been shown to explore different conformations. It has been proposed that Asn 254 dynamics could modulate W1 stability in the peroxo hole and favor its displacement out of the peroxo hole (McGregor et al., 2021). It is worth noting that this Asn residue is located between the active site and the hydrophobic cavity proposed to be a transient reservoir for di-oxygen close to the peroxo hole (Colloc'h \& Prangé, 2014). The HHP structures of UOX could then represent excited substates where Asn 254 moves backward to allow the di-oxygen to migrate from the hydrophobic cavity to the peroxo-hole.

We have suggested that the swelling of the active site can occur through the contraction of the neighboring hydrophobic cavity that has been proposed to act as a connecting vessel to give flexibility to the active site (Colloc'h \& Prangé, 2014; Girard et al., 2010). Its role is confirmed here in both the HHP and HArP structures. In the UOX-HHP-210-RT structure, the active site is enlarged, while the hydrophobic cavity volume is reduced. Conversely, in the UOX-HArP-200-T100 structure, the binding of argon in the cavity prevents its contraction and thus induces no enlargement of the active site. This confirms that argon restrains the intrinsic flexibility of the cavity. Consequently, the proton shuttle is not weakened when Ar is bound in the internal cavity, as was the case in HHP structures.

Accordingly, the argon atom bound in the hydrophobic cavity prevents the enlargement of the active site, thus stabilizing the UOX tetramer against pressure effects.

\subsection{Pressure inhibits substrate affinity of the enzyme}

Pressure has been shown to both enhance or inhibit enzymatic activities (Eisenmenger \& Reyes-DeCorcuera, 2009; Akasaka et al., 2008; Winter, 2019). For example, it can promote or hamper a 
catalytically active state of an enzyme with a better/lower ligand binding affinity or improve/reduce reaction rates by increasing/decreasing conformational flexibility. In the present case, enzymatic assays under pressure have previously shown that pressure decreases the enzymatic activity of UOX with a loss of substrate affinity, while the catalytic efficiency was unmodified and the protein was still tetrameric (Girard et al., 2010). Moreover, it was shown by electron spin resonance spectroscopy and quantum mechanical studies that residues from the face-to-face A-B interface participate in the stabilization of the active site (Gabison et al., 2011). The loss of substrate affinity induced by pressure might thus be explained by both the contraction of the allosteric cavity leading to the swelling in the active site and the destabilization of the face-to-face A-B interface.

\section{Conclusion}

Both ways of applying pressure, either per se (HHP) or noble-gas mediated (HArP), provide complementary information about the UOX mechanism. The UOX-HArP structures show that upon pressure, UOX does not transit directly from a tetrameric association to a monomeric form, but via a transient dimeric intermediate state constituted of the 16-stranded $\beta$-barrel built by the $\mathrm{A}$ and $\mathrm{C}$ chains. Very high argon pressures (above $22 \mathrm{MPa}$ ) thus allow the characterization of this intermediate excited sub-state with a partial unfolding behavior.

This study also highlights that high pressure applied to a protein-ligand complex, whatever the transmission medium, shifts the thermodynamic equilibrium towards the completion of the complex formation, according to Le Chatelier's principle. Pressure leads to the saturation of this complex and populates new specific sites within the protein. The comparison between the structures under high hydrostatic pressure per se, in which the cavity is empty, and the structures under high argon pressure, in which argon is bound, demonstrates the role of the allosteric cavity that provides the functional flexibility to the active site, necessary for the catalytic process.

High pressure NMR experiments have widely been used to characterize oligomeric states upon unfolding and to analyze structural perturbations and unfolding transitions. Here we show that crystallography under pressure (HPMX) is a valuable complementary tool which gives additional understanding in analyzing the structural perturbations at atomic level, and is even able to catch the first steps of the oligomeric dissociation preceding denaturation in the case of multimeric proteins like urate oxidase. 


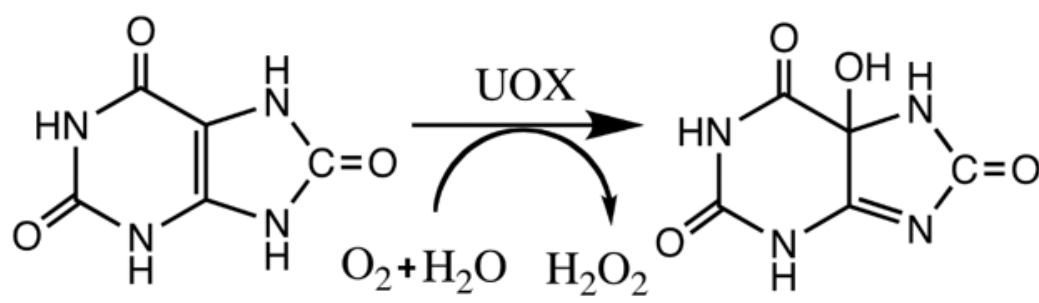<smiles></smiles>

Scheme 1 Left: The reaction catalysed by urate oxidase (UOX) from uric acid to 5-hydroxy-isourate. Right: The analogue 8-azaxanthine in which the 8-carbonyl group is replaced by a nitrogen atom.

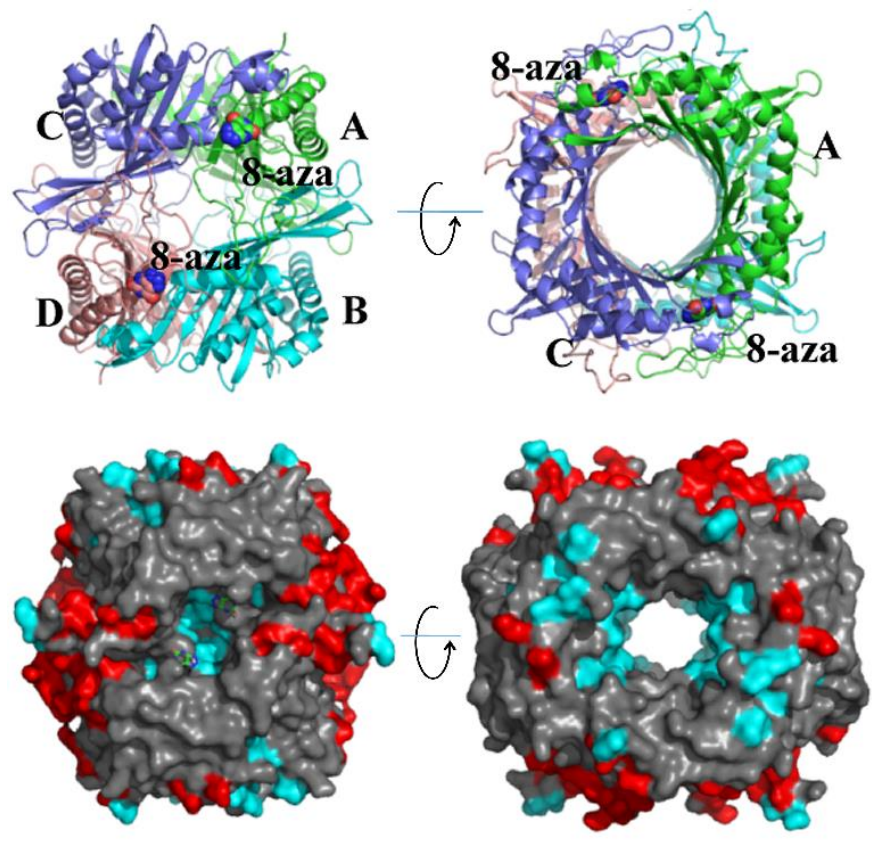

Figure 1 Upper left: The tetramer of urate oxidase in cartoon representation with the A chain in green, the $\mathrm{B}$ chain in cyan, the $\mathrm{C}$ chain in slate, and the $\mathrm{D}$ chain in salmon. The 8-azaxanthine molecules are shown in sphere representation. Upper right: Same representation, viewed along the central tunnel. Lower left: Molecular surface of UOX tetramer, colored in red where the $B$-factors increase more than $13 \AA^{2}$ between the UOX-HHP-0.1-RT and UOX-HHP-210-RT structures, in cyan where the $B$-factors increase less than $5 \AA^{2}$ and in grey otherwise. The 8-azaxanthine molecules are shown in ball-and-stick representation. Lower right: Same representation, viewed along the central tunnel. 


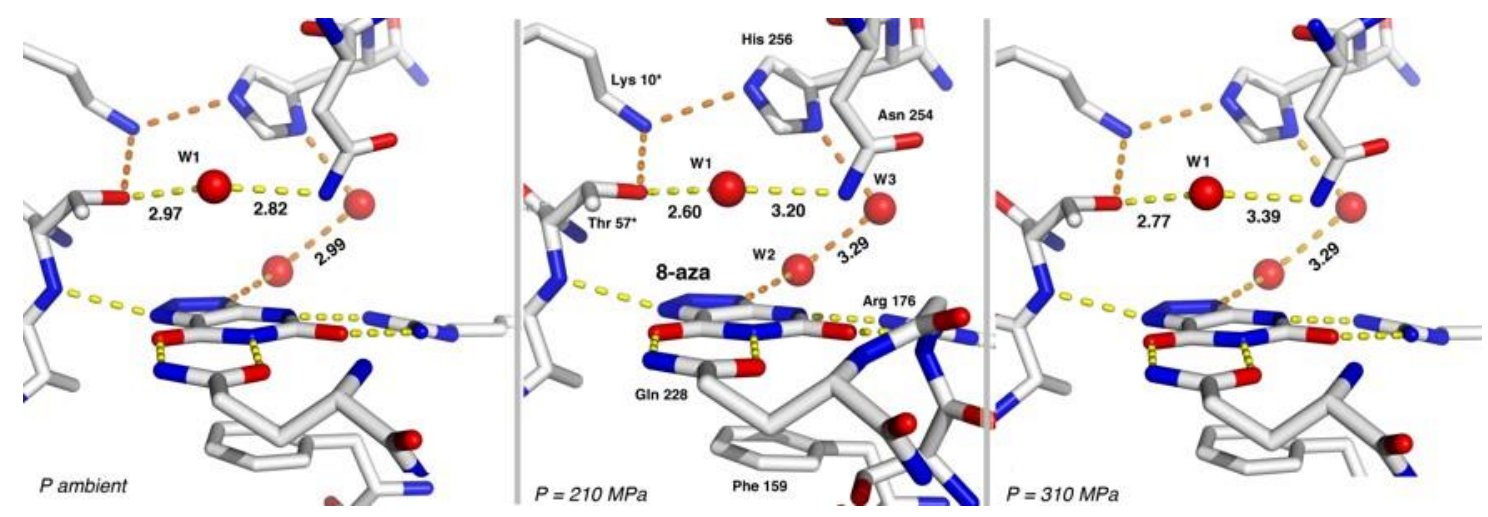

Figure 2 From left to right, the active site in the UOX-HPP-0.1-RT, UOX-HPP-210-RT and UOXHPP-310-RT structures, showing the progressive elongation of the catalytic water W1 tweezers and of the hydrogen bond between W2 and W3.
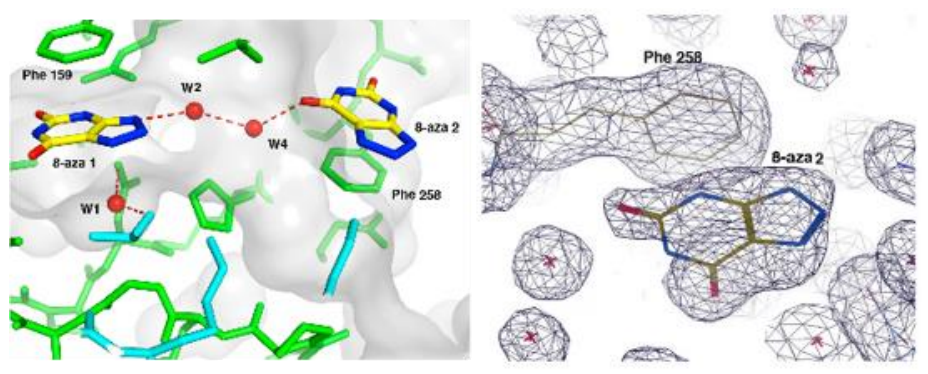

Figure 3 Left: In the UOX-HHP-210-RT, UOX-HHP-310-RT and UOX-HArP-200-T100 structures, the second ligand molecule ( 8 -aza 2 ) is located within the channel ending at the active site occupied by 8 -aza 1. It is connected to the first ligand through the two water molecules W2 and W4 and is stacked over Phe 258. Right: The electron density of the second ligand observed in the HArP-200-T100 structure (2Fo-Fc map, level at 1.5 sigmas above background). 

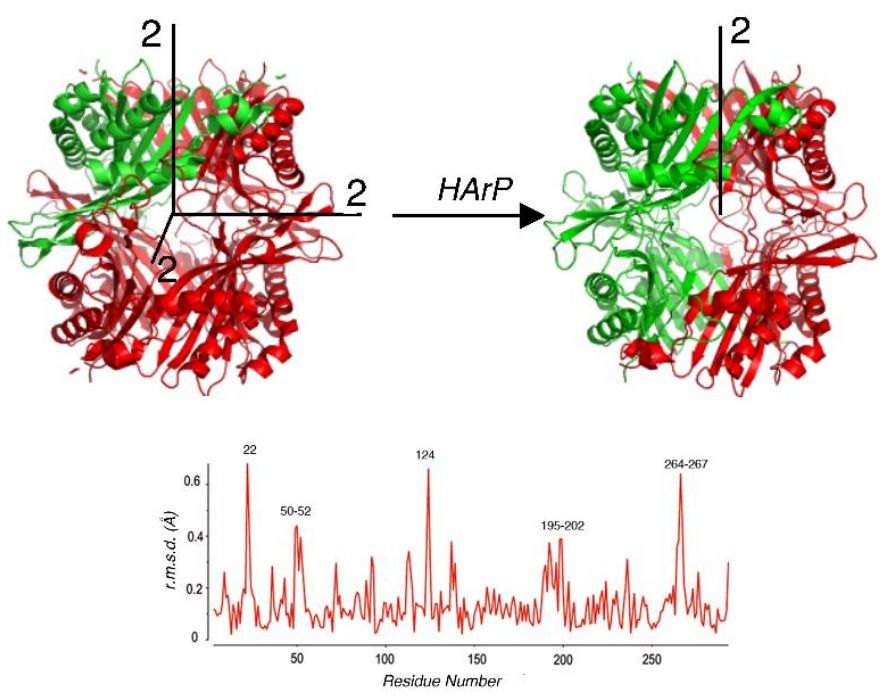

Figure 4 Upper: View of the HArP transition from an $\alpha 4$ tetramer with three 2 -fold axes (left, either the UOX-HPP-RT structures or the UOX-HArP structures up to $22 \mathrm{MPa}$ ) to a less-ordered $(\alpha \beta) 2$ tetramer with one two-fold axis (right, the UOX-HArP structures at $60 \mathrm{MPa}$ and above). The asymmetric units are coloured in green and the symmetry-generated subunits in the tetramer are coloured in red. Lower: The r.m.s. deviations of the two $\alpha$ and $\beta$ subunits of the UOX-HArP-200-T100 structure, relevant to the loss of the 2 -fold symmetry between them. 
Table 1 Data collection and processing statistics

Values for the outer shell are given in parentheses.

\begin{tabular}{|c|c|c|c|c|c|c|c|c|c|c|c|}
\hline Acronym & $\begin{array}{c}\text { UOX- } \\
\text { HHP- } \\
0.1- \\
\text { RT }\end{array}$ & $\begin{array}{c}\text { UOX- } \\
\text { HHP- } \\
210- \\
\text { RT }\end{array}$ & $\begin{array}{c}\text { UOX- } \\
\text { HHP- } \\
310- \\
\text { RT }\end{array}$ & $\begin{array}{c}\text { UOX- } \\
\text { HArP- } \\
3.5- \\
\text { RT }\end{array}$ & $\begin{array}{c}\text { UOX- } \\
\text { HArP- } \\
6.5- \\
\text { RT }\end{array}$ & $\begin{array}{c}\text { UOX- } \\
\text { HArP- } \\
12- \\
\text { T100 }\end{array}$ & $\begin{array}{c}\text { UOX- } \\
\text { HArP- } \\
22- \\
\text { T100 }\end{array}$ & $\begin{array}{c}\text { UOX- } \\
\text { HArP- } \\
60- \\
\text { T100 }\end{array}$ & $\begin{array}{c}\text { UOX- } \\
\text { HArP- } \\
100- \\
\text { T100 }\end{array}$ & $\begin{array}{c}\text { UOX- } \\
\text { HArP- } \\
150- \\
\text { T100 }\end{array}$ & $\begin{array}{c}\text { UOX- } \\
\text { HArP- } \\
200- \\
\text { T100 }\end{array}$ \\
\hline Diffraction source & \multicolumn{3}{|c|}{ SOLEIL, CRISTAL beamline } & \multicolumn{2}{|c|}{$\begin{array}{l}\text { MAXII, I711 } \\
\text { beamline }\end{array}$} & \multicolumn{6}{|c|}{ ESRF, ID30 beamline } \\
\hline Wavelength $(\AA)$ & 0.5818 & 0.5818 & 0.5818 & 0.9775 & 0.9775 & 1.77 & 1.77 & 1.77 & 1.77 & 1.77 & 1.77 \\
\hline Pressure (MPa) & 0.1 & 210 & 310 & 3.5 & 6.5 & 12 & 22 & 60 & 100 & 150 & 200 \\
\hline Temperature (K) & 291 & 291 & 291 & 291 & 291 & 100 & 100 & 100 & 100 & 100 & 100 \\
\hline Space group & $\mathrm{I} 222$ & $\mathrm{I} 222$ & $\mathrm{I} 222$ & $\mathrm{I} 222$ & $\mathrm{I} 222$ & $\mathrm{I} 222$ & $\mathrm{I} 222$ & $\mathrm{P} 2{ }_{1} 2_{12}$ & $\mathrm{P} 2{ }_{1} 2_{1} 2$ & $\mathrm{P} 22_{1} 2$ & $\mathrm{P} 2{ }_{1} 2{ }_{1}$ \\
\hline$a(\AA)$ & 80.34 & 79.53 & 79.13 & 80.23 & 80.32 & 80.89 & 79.79 & 78.23 & 78.43 & 77.40 & 78.55 \\
\hline$b(\AA)$ & 96.16 & 95.63 & 95.40 & 96.11 & 96.12 & 95.50 & 95.15 & 95.27 & 95.18 & 95.34 & 96.68 \\
\hline$c(\AA)$ & 105.51 & 104.75 & 104.67 & 105.39 & 105.41 & 105.23 & 104.28 & 104.5 & 104.4 & 104.66 & 105.58 \\
\hline Mosaicity $\left({ }^{\circ}\right)$ & 0.07 & 0.15 & 0.09 & 0.09 & 0.11 & 0.36 & 0.28 & 0.20 & 0.19 & 0.22 & 0.34 \\
\hline Resolution range $(\AA)$ & $\begin{array}{c}29.77- \\
1.90\end{array}$ & $\begin{array}{l}29.59- \\
2.15\end{array}$ & $\begin{array}{c}29.51- \\
2.40\end{array}$ & $\begin{array}{c}4.78- \\
1.60\end{array}$ & $\begin{array}{l}20.00- \\
1.60\end{array}$ & $\begin{array}{l}40.50- \\
2.36\end{array}$ & $\begin{array}{l}70.00- \\
1.69\end{array}$ & $\begin{array}{l}47.60- \\
1.86\end{array}$ & $\begin{array}{c}47.60- \\
1.64\end{array}$ & $\begin{array}{c}47.70- \\
2.19\end{array}$ & $\begin{array}{l}71.32- \\
1.72\end{array}$ \\
\hline $\begin{array}{l}\text { Total No of } \\
\text { reflections }\end{array}$ & $\begin{array}{c}107997 \\
(150493)\end{array}$ & $\begin{array}{c}69635 \\
(10163)\end{array}$ & $\begin{array}{l}51523 \\
(7586)\end{array}$ & $\begin{array}{l}220558 \\
(21323)\end{array}$ & $\begin{array}{l}187218 \\
(18022)\end{array}$ & $\begin{array}{l}175236 \\
(15472)\end{array}$ & $\begin{array}{c}490648 \\
(7193)\end{array}$ & $\begin{array}{l}607475 \\
(1545)\end{array}$ & $\begin{array}{l}908151 \\
(19326)\end{array}$ & $\begin{array}{l}405680 \\
(11521)\end{array}$ & $\begin{array}{l}531793 \\
\left(\begin{array}{lll}1 & 199\end{array}\right)\end{array}$ \\
\hline $\begin{array}{l}\text { No of unique } \\
\text { reflections }\end{array}$ & $\begin{array}{l}30145 \\
\left(\begin{array}{ll}4 & 400)\end{array}\right)\end{array}$ & $\begin{array}{l}21075 \\
\left(\begin{array}{ll}3 & 071\end{array}\right)\end{array}$ & $\begin{array}{l}15109 \\
(2216)\end{array}$ & $\begin{array}{l}53681 \\
(5277)\end{array}$ & $\begin{array}{l}52954 \\
(5301)\end{array}$ & $\begin{array}{l}47439 \\
(4 \quad 120)\end{array}$ & $\begin{array}{l}39125 \\
(2310)\end{array}$ & $\begin{array}{c}53842 \\
(499)\end{array}$ & $\begin{array}{l}84438 \\
(4955)\end{array}$ & $\begin{array}{c}39208 \\
(11521)\end{array}$ & $\begin{array}{l}73215 \\
(2671)\end{array}$ \\
\hline
\end{tabular}




\begin{tabular}{|c|c|c|c|c|c|c|c|c|c|c|c|}
\hline Completness (\%) & $\begin{array}{c}93.3 \\
(94.2)\end{array}$ & $\begin{array}{c}96.0 \\
(97.1)\end{array}$ & $\begin{array}{c}96.0 \\
(97.2)\end{array}$ & $\begin{array}{c}99.5 \\
(99.6)\end{array}$ & $\begin{array}{c}98.0 \\
(99.5)\end{array}$ & $\begin{array}{c}97.3 \\
(98.9)\end{array}$ & $\begin{array}{c}87.8 \\
(36.3)\end{array}$ & $\begin{array}{c}81.5 \\
(21.1)\end{array}$ & $\begin{array}{c}88.6 \\
(36.3)\end{array}$ & $\begin{array}{c}97.2 \\
(76.9)\end{array}$ & $\begin{array}{c}93.8 \\
(56.5)\end{array}$ \\
\hline Multiplicity & $\begin{array}{c}3.6 \\
(3.5)\end{array}$ & $\begin{array}{c}3.3 \\
(3.3)\end{array}$ & $\begin{array}{c}3.4 \\
(3.4)\end{array}$ & $\begin{array}{c}4.1 \\
(4.1)\end{array}$ & $\begin{array}{c}3.5 \\
(3.3)\end{array}$ & $\begin{array}{c}4.8 \\
(4.4)\end{array}$ & $\begin{array}{l}12.5 \\
(3.1)\end{array}$ & $\begin{array}{l}11.3 \\
(2.8)\end{array}$ & $\begin{array}{l}10.8 \\
(3.9)\end{array}$ & $\begin{array}{l}10.3 \\
(4.4)\end{array}$ & $\begin{array}{l}11.4 \\
(5.3)\end{array}$ \\
\hline Mean $\mathrm{I} / \sigma(\mathrm{I})$ & $\begin{array}{c}6.5 \\
(2.2)\end{array}$ & $\begin{array}{c}5.6 \\
(1.8)\end{array}$ & $\begin{array}{c}7.0 \\
(1.9)\end{array}$ & $\begin{array}{l}18.5 \\
(2.8)\end{array}$ & $\begin{array}{l}19.3 \\
(2.2)\end{array}$ & $\begin{array}{c}8.2 \\
(1.4)\end{array}$ & $\begin{array}{l}31.3 \\
(2.5)\end{array}$ & $\begin{array}{l}21.4 \\
(3.1)\end{array}$ & $\begin{array}{l}16.0 \\
(1.9)\end{array}$ & $\begin{array}{c}9.2 \\
(1.2)\end{array}$ & $\begin{array}{l}22.8 \\
(2.0)\end{array}$ \\
\hline$R_{\text {meas }}$ & $\begin{array}{c}15.8 \\
(60.2)\end{array}$ & $\begin{array}{c}21.2 \\
(83.5)\end{array}$ & $\begin{array}{c}16.5 \\
(75.1)\end{array}$ & $\begin{array}{c}4.0 \\
(26.0)\end{array}$ & $\begin{array}{c}6.3 \\
(59.9)\end{array}$ & $\begin{array}{c}9.9 \\
(85.3)\end{array}$ & $\begin{array}{c}6.3 \\
(20.9)\end{array}$ & $\begin{array}{c}6.6 \\
(35.6)\end{array}$ & $\begin{array}{c}8.5 \\
(58.6)\end{array}$ & $\begin{array}{c}16.2 \\
(81.1)\end{array}$ & $\begin{array}{c}12.7 \\
(55.2)\end{array}$ \\
\hline$R_{\text {r.i.m }} \dagger^{\dagger}$ & $\begin{array}{c}0.158 \\
(0.608)\end{array}$ & $\begin{array}{c}0.208 \\
(0.840)\end{array}$ & $\begin{array}{c}0.165 \\
(0.756)\end{array}$ & $\begin{array}{c}0.040 \\
(0.260)\end{array}$ & $\begin{array}{c}0.063 \\
(0.599)\end{array}$ & $\begin{array}{c}0.099 \\
(0.853)\end{array}$ & $\begin{array}{c}0.063 \\
(0.209)\end{array}$ & $\begin{array}{c}0.064 \\
(0.202)\end{array}$ & $\begin{array}{c}0.085 \\
(0.591)\end{array}$ & $\begin{array}{c}0.170 \\
(1.044)\end{array}$ & $\begin{array}{l}0.062 \\
(0.63)\end{array}$ \\
\hline $\mathrm{CC}_{1 / 2}$ & $\begin{array}{c}99.0 \\
(80.5)\end{array}$ & $\begin{array}{c}98.5 \\
(69.8)\end{array}$ & $\begin{array}{c}98.8 \\
(69.8)\end{array}$ & & & $\begin{array}{c}99.9 \\
(44.4)\end{array}$ & $\begin{array}{c}99.9 \\
(97.9)\end{array}$ & $\begin{array}{c}99.8 \\
(96.9)\end{array}$ & $\begin{array}{c}99.7 \\
(80.0)\end{array}$ & $\begin{array}{c}99.0 \\
(77.3)\end{array}$ & $\begin{array}{c}99.6 \\
(80.8)\end{array}$ \\
\hline Overall B factor $\left(\AA^{2}\right)$ & 17.5 & 26.7 & 37.7 & 24.5 & 25.5 & 53.4 & 18.1 & 16.9 & 19.1 & 25.4 & 33.2 \\
\hline
\end{tabular}

$\dagger$ Estimated $R_{\text {r.i.m. }}=R_{\text {merge }}[N /(N-1)]^{1 / 2}$, where $N=$ data multiplicity. 
Table 2 Structure solution and refinement statistics

Values for the outer shell are given in parentheses.

\begin{tabular}{|c|c|c|c|c|c|c|c|c|c|c|c|}
\hline Acronym & $\begin{array}{c}\text { UOX- } \\
\text { HHP- } \\
0.1-R T\end{array}$ & $\begin{array}{c}\text { UOX- } \\
\text { HHP- } \\
\text { 210-RT }\end{array}$ & $\begin{array}{l}\text { UOX- } \\
\text { HHP- } \\
\text { 310-RT }\end{array}$ & $\begin{array}{l}\text { UOX- } \\
\text { HArP- } \\
\text { 3.5-RT }\end{array}$ & $\begin{array}{l}\text { UOX- } \\
\text { HArP- } \\
6.5-R T\end{array}$ & $\begin{array}{c}\text { UOX- } \\
\text { HArP- } \\
\text { 12-T100 }\end{array}$ & $\begin{array}{c}\text { UOX- } \\
\text { HArP- } \\
22-T 100\end{array}$ & $\begin{array}{c}\text { UOX- } \\
\text { HArP- } \\
\text { 60-T100 }\end{array}$ & $\begin{array}{c}\text { UOX- } \\
\text { HArP- } \\
\text { 100-T100 }\end{array}$ & $\begin{array}{c}\text { UOX- } \\
\text { HArP- } \\
\text { 150-T100 }\end{array}$ & $\begin{array}{c}\text { UOX- } \\
\text { HArP- } \\
200-T 100\end{array}$ \\
\hline $\begin{array}{l}\text { Resolution range } \\
(\AA)\end{array}$ & $\begin{array}{c}20.0- \\
1.90\end{array}$ & $\begin{array}{l}20.0- \\
2.15\end{array}$ & $\begin{array}{c}20.0- \\
2.40\end{array}$ & $\begin{array}{c}14.78- \\
1.60\end{array}$ & $\begin{array}{c}14.42- \\
1.60\end{array}$ & $\begin{array}{c}40.48- \\
2.36\end{array}$ & $\begin{array}{l}70.0- \\
1.69\end{array}$ & $\begin{array}{c}47.70- \\
1.86\end{array}$ & $\begin{array}{c}47.65- \\
1.64\end{array}$ & $\begin{array}{c}47.70- \\
2.19\end{array}$ & $\begin{array}{c}46.38- \\
1.80\end{array}$ \\
\hline $\begin{array}{l}\text { No of reflections, } \\
\text { working set }\end{array}$ & $\begin{array}{l}25754 \\
(1746)\end{array}$ & $\begin{array}{l}17795 \\
(1122)\end{array}$ & $\begin{array}{c}13313 \\
(869)\end{array}$ & $\begin{array}{l}50892 \\
(3677)\end{array}$ & $\begin{array}{l}50192 \\
(3714)\end{array}$ & $\begin{array}{c}14823 \\
(72)\end{array}$ & $\begin{array}{c}37292 \\
(668)\end{array}$ & $\begin{array}{c}51064 \\
(659)\end{array}$ & $\begin{array}{l}80214 \\
(1305)\end{array}$ & $\begin{array}{l}37198 \\
(2053)\end{array}$ & $\begin{array}{l}68695 \\
(3402)\end{array}$ \\
\hline $\begin{array}{l}\text { No of reflections, } \\
\text { test set }\end{array}$ & $\begin{array}{l}1390 \\
(83)\end{array}$ & $\begin{array}{l}944 \\
(57)\end{array}$ & $\begin{array}{l}693 \\
(50)\end{array}$ & $\begin{array}{l}2729 \\
(187)\end{array}$ & $\begin{array}{l}2707 \\
(173)\end{array}$ & $\begin{array}{l}739 \\
(8)\end{array}$ & $\begin{array}{c}1831 \\
(34)\end{array}$ & $\begin{array}{c}2726 \\
(34)\end{array}$ & $\begin{array}{c}4143 \\
(56)\end{array}$ & $\begin{array}{l}1959 \\
(124)\end{array}$ & $\begin{array}{l}3583 \\
(170)\end{array}$ \\
\hline Final Rcryst & $\begin{array}{c}0.174 \\
(0.269)\end{array}$ & $\begin{array}{c}0.189 \\
(0.309)\end{array}$ & $\begin{array}{c}0.188 \\
(0.349)\end{array}$ & $\begin{array}{c}0.151 \\
(0.206)\end{array}$ & $\begin{array}{c}0.156 \\
(0.300)\end{array}$ & $\begin{array}{c}0.198 \\
(0.863)\end{array}$ & $\begin{array}{c}0.154 \\
(0.646)\end{array}$ & $\begin{array}{c}0.165 \\
(0.227)\end{array}$ & $\begin{array}{c}0.177 \\
(0.297)\end{array}$ & $\begin{array}{c}0.174 \\
(0.317)\end{array}$ & $\begin{array}{c}0.212 \\
(0.386)\end{array}$ \\
\hline Final Rfree & $\begin{array}{c}0.222 \\
(0.316)\end{array}$ & $\begin{array}{c}0.248 \\
(0.340)\end{array}$ & $\begin{array}{c}0.270 \\
(0.366)\end{array}$ & $\begin{array}{c}0.178 \\
(0.245)\end{array}$ & $\begin{array}{c}0.183 \\
(0.305)\end{array}$ & $\begin{array}{c}0.264 \\
(1.154)\end{array}$ & $\begin{array}{c}0.196 \\
(0.673)\end{array}$ & $\begin{array}{c}0.208 \\
(0.225)\end{array}$ & $\begin{array}{c}0.205 \\
(0.361)\end{array}$ & $\begin{array}{c}0.226 \\
(0.333)\end{array}$ & $\begin{array}{c}0.243 \\
(0.391)\end{array}$ \\
\hline \multicolumn{12}{|l|}{ No of non-H atoms } \\
\hline Proteins & 2362 & 2362 & 2362 & 2362 & 2362 & 2362 & 2362 & 4724 & 4824 & 4829 & 4724 \\
\hline Ion & 1 & 1 & 1 & 1 & 1 & 1 & 6 & 2 & 2 & 2 & 2 \\
\hline Ligand & 11 & 22 & 22 & 11 & 11 & 20 & 16 & 17 & 22 & 44 & 44 \\
\hline Water & 261 & 179 & 115 & 229 & 221 & 203 & 435 & 531 & 652 & 580 & 473 \\
\hline Argon & - & - & - & 1 & 1 & 2 & 2 & 4 & 4 & 4 & 4 \\
\hline Total & 2635 & 2564 & 2500 & 2604 & 2596 & 2588 & 2821 & 5277 & 5504 & 5459 & 5247 \\
\hline
\end{tabular}




\begin{tabular}{|c|c|c|c|c|c|c|c|c|c|c|c|}
\hline Bonds $(\AA)$ & 0.019 & 0.014 & 0.013 & 0.013 & 0.013 & 0.003 & 0.016 & 0.007 & 0.008 & 0.006 & 0.006 \\
\hline Angles $\left(^{\circ}\right)$ & 1.808 & 1.66 & 1.461 & 1.873 & 1.917 & 0.999 & 2.512 & 1.31 & 1.33 & 1.29 & 1.324 \\
\hline \multicolumn{12}{|l|}{$\begin{array}{l}\text { Average B factors } \\
\left(\AA^{2}\right)\end{array}$} \\
\hline Proteins & 19.91 & 29.41 & 49.03 & 26 & 26.4 & 54.6 & 16.6 & 17.9 & 19.9 & 30.0 & 34.2 \\
\hline Ion & 22.26 & 31.35 & 58.77 & 37.5 & 40.1 & 65.2 & 24.2 & 19.4 & 21 & 35.2 & 42.3 \\
\hline Ligand & 11.88 & 31 & 41.18 & 26.3 & 28.2 & 54.1 & 19.3 & 11.0 & 14.2 & 30.1 & 37.4 \\
\hline Water & 34.67 & 35.04 & 44.6 & 39.2 & 38.7 & 53.5 & 28.5 & 27.3 & 29 & 39.7 & 37.3 \\
\hline \multicolumn{12}{|l|}{$\begin{array}{l}\text { Ramachandran } \\
\text { diagram }\end{array}$} \\
\hline Most favored (\%) & 96.8 & 97.5 & 95.4 & 96.6 & 96.9 & 94.7 & 96.8 & 96.1 & 96.1 & 94.6 & 96.2 \\
\hline Allowed (\%) & 3.2 & 2.5 & 4.3 & 3.0 & 2.7 & 4.9 & 3.2 & 3.6 & 3.6 & 5.4 & 3.4 \\
\hline PDB accession ID & $7 p 0 g$ & $7 p 0 c$ & $7 p 0 d$ & $6 i 9 x$ & $6 i 9 z$ & 6ial & $6 i a 3$ & $7 p u f$ & $7 p w n$ & $7 q 09$ & $6 i a 9$ \\
\hline
\end{tabular}


Acknowledgements The authors acknowledge the SOLEIL (Gif-sur-Yvette, France), the European Synchrotron Radiation Facility (ESRF, (Grenoble, France) and the MAX II synchrotrons (Lund, Sweden) for provision of synchrotron radiation facilities. They thank Pierre Fertey of the CRISTAL beamline (SOLEIL) for his technical help and assistance during data collection under high pressure per se, Yngve Cerenius and the staff members of I117 beamline (MAX II) for data collection in quartz capillaries under moderate argon pressure, and the staff members of ID30-B beamline (ESRF) for data collection under high argon pressure. The authors acknowledge access to the ESRF MX high-pressure laboratory for the preparation of the frozen UOX crystals under argon pressure. The use of the different large aperture DACs built by BETSA has been made possible through the IBS High Pressure platform. IBS acknowledges integration into the interdisciplinary Research Institute of Grenoble (IRIG, CEA). The authors also have special thoughts for Roger Fourme, deceased in 2012, who developed HPMX with such great enthusiasm.

\section{References}

Akasaka, K. (2006). Chem. Rev. 106, 1814-1835.

Akasaka, K., Kitahara, R. \& Kamatari, Y. O. (2013). Arch. Biochem. Biophys. 531, 110-115.

Akasaka, K., Nagahata, H., Maeno, A. \& Sasaki, K. (2008). Biophysics (Nagoya-Shi). 4, 29 32.

Bliznyuk, A., Grossman, Y. \& Moskovitz, Y. (2019). Sci Rep. 9, 10814.

Bui, S., von Stetten, D., Jambrina, P. G., Prangé, T., Colloc'h, N., de Sanctis, D., Royant, A., Rosta, E. \& Steiner, R. A. (2014). Angew. Chem. Int. Ed. Engl. 53, 13710-13714.

Bury, C. S., Brooks-Bartlett, J. C., Walsh, S. P. \& Garman, E. F. (2018). Protein Sci. 27, 217-228.

Collins, M. D., Hummer, G., Quillin, M. L., Matthews, B. W. \& Gruner, S. M. (2005). Proc. Natl. Acad. Sci. U.S.A. 102, 16668-16671.

Collins, M. D., Kim, C. U. \& Gruner, S. M. (2011). Annu Rev Biophys. 40, 81-98.

Colloc'h, N., Carpentier, P., Montemiglio, L. C., Vallone, B. \& Prangé, T. (2017). Biophys. J. 113, 2199-2206.

Colloc'h, N., el Hajji, M., Bachet, B., L’Hermite, G., Schiltz, M., Prangé, T., Castro, B. \& Mornon, J. P. (1997). Nat. Struct. Biol. 4, 947-952. 
Colloc'h, N., Marassio, G. \& Prangé, T. (2011). Current Trends in X-Ray Crystallography, Vol. edited by A. Chandrasekaran, pp. 285-308. InTech.

Colloc'h, N. \& Prangé, T. (2014). FEBS Lett. 588, 1715-1719.

Dhaussy, A.-C. \& Girard, E. (2015). Subcell Biochem. 72, 215-235.

Eisenmenger, M. J. \& Reyes-De-Corcuera, J. I. (2009). Enzyme and Microbial Technology. 45, 331-347.

Emsley, P., Lohkamp, B., Scott, W. G. \& Cowtan, K. (2010). Acta Crystallogr D Biol Crystallogr. 66, 486-501.

Engilberge, S., Wagner, T., Carpentier, P., Girard, E. \& Shima, S. (2020). Chem Commun (Camb). 56, 10863-10866.

Espada, R., Sánchez, I. E. \& Ferreiro, D. U. (2016). Biophys. J. 111, 2339-2341.

Fourme, R., Girard, E. \& Akasaka, K. (2012). Curr. Opin. Struct. Biol. 22, 636-642.

Fourme, R., Girard, E., Kahn, R., Dhaussy, A.-C. \& Ascone, I. (2009). Annu Rev Biophys. 38, 153-171.

Fourme, R., Honkimäki, V., Girard, E., Medjoubi, K., Dhaussy, A.-C. \& Kahn, R. (2012). J Appl Cryst. 45, 652-661.

Fourme, R., Kahn, R., Mezouar, M., Girard, E., Hoerentrup, C., Prangé, T. \& Ascone, I. (2001). J Synchrotron Radiat. 8, 1149-1156.

Frauenfelder, H., Alberding, N., Ansari, A., Braunstein, D., Cowen, B., Hong, M., Iben, I., Johnson, J., Luck, S., Marden, M., Mourant, J., Ormos, P., Reinisch, L., Scholl, R., Schulte, A., Shyamsunder, E., Sorensen, L., Steinbach, P., Xie, A., Young, R. \& Yue, K. (1990). J. Phys. Chem. 1024-1037.

Frauenfelder, H., Chen, G., Berendzen, J., Fenimore, P. W., Jansson, H., McMahon, B. H., Stroe, I. R., Swenson, J. \& Young, R. D. (2009). Proc. Natl. Acad. Sci. U.S.A. 106, 5129-5134.

Frauenfelder, H., Fenimore, P. W. \& Young, R. D. (2007). IUBMB Life. 59, 506-512.

Fuglestad, B., Stetz, M. A., Belnavis, Z. \& Wand, A. J. (2017). Biophysical Chemistry. 231, 39-44.

Gabison, L., Chiadmi, M., El Hajji, M., Castro, B., Colloc'h, N. \& Prangé, T. (2010). Acta Crystallogr. D Biol. Crystallogr. 66, 714-724.

Gabison, L., Chopard, C., Colloc'h, N., Peyrot, F., Castro, B., El Hajji, M., Altarsha, M., Monard, G., Chiadmi, M. \& Prangé, T. (2011). Proteins. 79, 1964-1976.

Gabison, L., Prangé, T., Colloc'h, N., El Hajji, M., Castro, B. \& Chiadmi, M. (2008). BMC Struct. Biol. 8, 32. 
Girard, E., Dhaussy, A.-C., Couzinet, B., Chervin, J.-C., Mezouar, M., Kahn, R., Ascone, I. \& Fourme, R. (2007). J Appl Crystallogr. 40, 912-918.

Girard, E., Marchal, S., Perez, J., Finet, S., Kahn, R., Fourme, R., Marassio, G., Dhaussy, A.C., Prangé, T., Giffard, M., Dulin, F., Bonneté, F., Lange, R., Abraini, J. H., Mezouar, M. \& Colloc'h, N. (2010). Biophys. J. 98, 2365-2373.

Gotthard, G., Aumonier, S., De Sanctis, D., Leonard, G., von Stetten, D. \& Royant, A. (2019). IUCrJ. 6, 665-680.

Hahn, C. J., Lemaire, O. N., Kahnt, J., Engilberge, S., Wegener, G. \& Wagner, T. (2021). Science. 373, 118-121.

Hibi, T., Hayashi, Y., Fukada, H., Itoh, T., Nago, T. \& Nishiya, Y. (2014). Biochemistry. 53, 3879-3888.

Hibi, T. \& Itoh, T. (2021). J Biochem. 169, 15-23.

Hibi, T., Kume, A., Kawamura, A., Itoh, T., Fukada, H. \& Nishiya, Y. (2016). Biochemistry. 55, 724-732.

Kabsch, W. (2010). Acta Crystallogr. D Biol. Crystallogr. 66, 125-132.

Kalbitzer, H. R., Rosnizeck, I. C., Munte, C. E., Narayanan, S. P., Kropf, V. \& Spoerner, M. (2013). Angew. Chem. Int. Ed. Engl. 52, 14242-14246.

Kalms, J., Schmidt, A., Frielingsdorf, S., van der Linden, P., von Stetten, D., Lenz, O., Carpentier, P. \& Scheerer, P. (2016). Angew. Chem. Int. Ed. Engl. 55, 5586-5590.

Kleywegt, G. J. \& Jones, T. A. (1994). Acta Crystallogr. D Biol. Crystallogr. 50, 178-185.

Knapp, J. E., Pahl, R., Cohen, J., Nichols, J. C., Schulten, K., Gibson, Q. H., Srajer, V. \& Royer, W. E., Jr (2009). Structure. 17, 1494-1504.

Krissinel, E. (2015). Nucleic Acids Res. 43, W314-319.

Lafumat, B., Mueller-Dieckmann, C., Leonard, G., Colloc'h, N., Prangé, T., Giraud, T., Dobias, F., Royant, A., van der Linden, P. \& Carpentier, P. (2016). Journal of Applied Crystallography. 49, 1478-1487.

Leal, R. M. F., Bourenkov, G., Russi, S. \& Popov, A. N. (2013). J Synchrotron Radiat. 20, $14-22$.

Levin, A., Cinar, S., Paulus, M., Nase, J., Winter, R. \& Czeslik, C. (2019). Biophys Chem. 252, 106194.

van der Linden, P., Dobias, F., Vitoux, H., Kapp, U., Jacobs, J., Sweeney, S. M., MuellerDieckmann, C. \& Carpentier, P. (2014). Journal of Applied Crystallography. 47, 584592.

Louis, J. M. \& Roche, J. (2016). J Mol Biol. 428, 2780-2792. 
Luna, V. M., Chen, Y., Fee, J. A. \& Stout, C. D. (2008). Biochemistry. 47, 4657-4665.

Luna, V. M., Fee, J. A., Deniz, A. A. \& Stout, C. D. (2012). Biochemistry. 51, 4669-4676.

Luong, T. Q., Kapoor, S. \& Winter, R. (2015). Chemphyschem. 16, 3555-3571.

Marassio, G., Prangé, T., David, H. N., Sopkova-de Oliveira Santos, J., Gabison, L., Delcroix, N., Abraini, J. H. \& Colloc'h, N. (2011). FASEB J. 25, 2266-2275.

McCarthy, A. A., Barrett, R., Beteva, A., Caserotto, H., Dobias, F., Felisaz, F., Giraud, T., Guijarro, M., Janocha, R., Khadrouche, A., Lentini, M., Leonard, G. A., Lopez Marrero, M., Malbet-Monaco, S., McSweeney, S., Nurizzo, D., Papp, G., Rossi, C., Sinoir, J., Sorez, C., Surr, J., Svensson, O., Zander, U., Cipriani, F., Theveneau, P. \& Mueller-Dieckmann, C. (2018). J Synchrotron Radiat. 25, 1249-1260.

McGregor, L., Földes, T., Bui, S., Moulin, M., Coquelle, N., Blakeley, M. P., Rosta, E. \& Steiner, R. A. (2021). IUCrJ. 8, 46-59.

Montet, Y., Amara, P., Volbeda, A., Vernede, X., Hatchikian, E. C., Field, M. J., Frey, M. \& Fontecilla-Camps, J. C. (1997). Nat Struct Biol. 4, 523-526.

de la Mora, E., Coquelle, N., Bury, C. S., Rosenthal, M., Holton, J. M., Carmichael, I., Garman, E. F., Burghammer, M., Colletier, J.-P. \& Weik, M. (2020). Proc Natl Acad Sci U S A. 117, 4142-4151.

Murshudov, G. N., Vagin, A. A. \& Dodson, E. J. (1997). Acta Crystallogr D Biol Crystallogr. 53, 240-255.

Nagae, T., Kawamura, T., Chavas, L. M. G., Niwa, K., Hasegawa, M., Kato, C. \& Watanabe, N. (2012). Acta Crystallogr. D Biol. Crystallogr. 68, 300-309.

Nielsen, G., Jonker, H. R. A., Vajpai, N., Grzesiek, S. \& Schwalbe, H. (2013). Chembiochem. 14, 1799-1806.

Prangé, T., Schiltz, M., Pernot, L., Colloc'h, N., Longhi, S., Bourguet, W. \& Fourme, R. (1998). Proteins. 30, 61-73.

Quillin, M. L., Breyer, W. A., Griswold, I. J. \& Matthews, B. W. (2000). J. Mol. Biol. 302, 955-977.

Schiltz, M., Fourme, R. \& Prangé, T. (2003). Methods Enzymol. 374, 83-119.

Schiltz, M., Prangé, T. \& Fourme, R. (1994). J Appl Cryst. 27, 950-960.

Silva, J. L. \& Weber, G. (1993). Annu Rev Phys Chem. 44, 89-113.

Storm, S. L. S., Axford, D. \& Owen, R. L. (2021). IUCrJ. 8,.

Tilton, R. F., Kuntz, I. D. \& Petsko, G. A. (1984). Biochemistry. 23, 2849-2857.

Vitali, J., Robbins, A. H., Almo, S. C. \& Tilton, R. F. (1991). J Appl Cryst. 24, 931-935. 
Wei, D., Huang, X., Qiao, Y., Rao, J., Wang, L., Liao, F. \& Zhan, C.-G. (2017). ACS Catal. 7, 4623-4636.

Whittington, D. A., Rosenzweig, A. C., Frederick, C. A. \& Lippard, S. J. (2001). Biochemistry. 40, 3476-3482.

Williamson, M. P. \& Kitahara, R. (2019). Biochim Biophys Acta Proteins Proteom. 1867, 350-358.

Winn, M. D., Ballard, C. C., Cowtan, K. D., Dodson, E. J., Emsley, P., Evans, P. R., Keegan, R. M., Krissinel, E. B., Leslie, A. G. W., McCoy, A., McNicholas, S. J., Murshudov, G. N., Pannu, N. S., Potterton, E. A., Powell, H. R., Read, R. J., Vagin, A. \& Wilson, K. S. (2011). Acta Crystallogr D Biol Crystallogr. 67, 235-242.

Winter, M. B., Herzik, M. A., Kuriyan, J. \& Marletta, M. A. (2011). Proc. Natl. Acad. Sci. U.S.A. 108, E881-889.

Winter, R. (2019). Аnnu Rev Biophys. 48, 441-463.

Xue, M., Wakamoto, T., Kejlberg, C., Yoshimura, Y., Nielsen, T. A., Risør, M. W., Sanggaard, K. W., Kitahara, R. \& Mulder, F. A. A. (2019). Proc Natl Acad Sci U S A. 116, 21031-21036. 